\title{
Article \\ Relationship between $\beta$-Carotene Accumulation and Geranylgeranyl Pyrophosphate Synthase in Different Species of Dunaliella
}

\author{
Lu Xu, Fan Gao, Jia Feng, Junping Lv, Qi Liu, Fangru Nan, Xudong Liu and Shulian Xie *D \\ School of Life Science, Shanxi University, Taiyuan 030006, China; x19858111@163.com (L.X.); \\ gaofan@sxu.edu.cn (F.G.); fengj@sxu.edu.cn (J.F.); lvjunping024@sxu.edu.cn (J.L.); liuqi@sxu.edu.cn (Q.L.); \\ nanfr@sxu.edu.cn (F.N.); liuxudong@sxu.edu.cn (X.L.) \\ * Correspondence: xiesl@sxu.edu.cn
}

check for

updates

Citation: Xu, L.; Gao, F.; Feng, J.; Lv, J.; Liu, Q.; Nan, F.; Liu, X.; Xie, S. Relationship between $\beta$-Carotene Accumulation and Geranylgeranyl Pyrophosphate Synthase in Different Species of Dunaliella. Plants 2022, 11, 27. https://doi.org/10.3390/ plants11010027

Academic Editors: Luca Forti, Laura Arru and Moreno Bondi

Received: 1 December 2021

Accepted: 20 December 2021

Published: 22 December 2021

Publisher's Note: MDPI stays neutral with regard to jurisdictional claims in published maps and institutional affiliations.

Copyright: (c) 2021 by the authors. Licensee MDPI, Basel, Switzerland. This article is an open access article distributed under the terms and conditions of the Creative Commons Attribution (CC BY) license (https:// creativecommons.org/licenses/by/ $4.0 /)$.

\begin{abstract}
To study the relationship between $\beta$-carotene synthesis and geranylgeranyl pyrophosphate synthase (GGPS) activity, 15 species of Dunaliella were used to determine the changes in photosynthetic pigment contents, chlorophyll fluorescence parameters, $\beta$-carotene content, and GGPS activity. By observing the morphology and size of 15 species of Dunaliella, D8 has the largest individual algal cell and D9 has the smallest individual. Growth was relatively slow during days one through seven. After about eight days, the cells entered the logarithmic growth period and grew rapidly to a high density. After about 45 days, they entered a mature period, and growth slowed down. The contents of chlorophyll, carotenoids, and $\beta$-carotene increased during growth. D1 has the highest accumulation of $\beta$-carotene, and GGPS enzyme activity has a positive linear relationship with the $\beta$-carotene synthesis content. Phylogenetic analysis showed that the GGPS proteins of the 15 species were highly homologous, and the GGPS protein was not part of the membrane.
\end{abstract}

Keywords: Dunaliella; $\beta$-carotene; geranylgeranyl pyrophosphate synthase

\section{Introduction}

Dunaliella (Chlorophyceae, Chlorophyta) [1] is a single-celled alga without cell walls $[2,3]$. Dunaliella is one of the most salt-tolerant eukaryotes found in nature. It exists in salt lakes, and 28 species have been reported. Dunaliella salina is often used as a model algal species [4].

Dunaliella has been used in food, health products, cosmetics, anti-cancer drugs, biotechnology and other fields [5-8]. The synthesis of fucoxanthin with $\beta$-carotene has great application prospects in anti-cancer, anti-inflammatory, and blood pressure reduction. In addition, other nutrients contained in the Dunaliella algae, such as proteins, amino acids, carbohydrates, and lipids, have great commercial development and economic value $[9,10]$.

$\beta$-carotene plays an important role in maintaining human health. Dunaliella salina is one of the important raw materials for the synthesis of $\beta$-carotene [11]. Synthesis of $\beta$-carotene is jointly regulated by a variety of enzymes, including isopentenyl diphosphate (IPP), dimethylallyl pyrophosphate (DMAPP), geranylgeranyl pyrophosphate synthase (GGPS), phytoene synthase (PSY), phytoene undergoes phytoene desaturase (PDS), $\zeta$-carotene dehydrogenation (ZDS), carotenoid isomerase (CRTISO), 15-cis- $\zeta$-isomerase (ZISO), and lycopene $\beta$-cyclase (LCYB) [12-14]. Among them, GGPS is the key enzyme in $\beta$-carotene synthesis.

No study has investigated the relationship between GGPS activity and $\beta$-carotene synthesis in the Dunaliella algae. In this study, 15 species of Dunaliella were cultured, and GGPS enzyme activity and $\beta$-carotene content were determined during the logarithmic and mature phases to determine the relationship between them. The results will provide a reference for further industrial production of the Dunaliella algae. 


\section{Materials and Methods}

\subsection{Algae Species and Cultivation}

A total of 15 Dunaliella species were obtained by sampling domestic saltwater lakes and purchasing from overseas algal banks. The details are shown in Table 1. Dunaliella medium was used to expand the Dunaliella algal cultures. The medium was prepared according to a previously published method, and the reagents and dosages required for use are shown in Table 2 [15]. All reagents used were analytically pure. The $\mathrm{pH}$ of the medium is 7.5, and the salinity is $87.69 \times 10^{-9} \mathrm{ppt}$. The Dunaliella species were incubated in a culture room at $25 \pm 2$ with fluorescent lamps at a light of $55.50 \mu \mathrm{mol} \mathrm{m}{ }^{-2} \mathrm{~s}^{-1}$ and a $12 \mathrm{~h}: 12 \mathrm{~h}$ light:dark cycle. During the cultivation process, the Erlenmeyer flask needs to be shaken evenly every day.

Table 1. Algae information for the 15 Dunaliella species.

\begin{tabular}{lll}
\hline No. & \multicolumn{1}{c}{ Strain } & \multicolumn{1}{c}{ Source } \\
\hline D1 & D. primolecta & Culture Collection of Algae and Protozoa (CCAP 11/34) \\
D2 & D. maritima & Culture Collection of Algae and Protozoa (CCAP 19/1) \\
D3 & D. peircei & Culture Collection of Algae and Protozoa (CCAP 19/2) \\
D4 & D. viridis & Culture Collection of Algae and Protozoa (CCAP 19/3) \\
D5 & D. bioculata & Culture Collection of Algae and Protozoa (CCAP 19/4) \\
D6 & D. quartolecta & Culture Collection of Algae and Protozoa (CCAP 19/8) \\
D7 & D. parva & Culture Collection of Algae and Protozoa (CCAP 19/10) \\
D8 & D. salina & Culture Collection of Algae and Protozoa (CCAP 19/12) \\
D9 & D. polymorpha & Culture Collection of Algae and Protozoa (CCAP 19/14) \\
D10 & D. tertiolecta & Culture Collection of Algae and Protozoa (CCAP 19/22) \\
D11 & D. acidophila & Culture Collection of Algae and Protozoa (CCAP 19/35) \\
D12 & D. bioculata_C33 & Culture Collection of Algae at the University of Texas at Austin \\
D13 & D. salina & (LB199) \\
D14 & Dunaliella sp. & Salt Lake in Yuncheng City, Shanxi Province \\
D15 & D. apiculata & Institute of Hydrobiology, Chinese Academy of Sciences \\
\end{tabular}

Table 2. Dunaliella medium.

\begin{tabular}{|c|c|c|}
\hline Formulate Content & Components & Dosage \\
\hline \multirow{9}{*}{ Dunaliella medium } & $\mathrm{NaCl}$ & $87.69 \mathrm{~g}$ \\
\hline & $\mathrm{NaNO}_{3}$ & $0.42 \mathrm{~g}$ \\
\hline & $\mathrm{NaH}_{2} \mathrm{PO}_{4} \cdot 2 \mathrm{H}_{2} \mathrm{O}$ & $0.0156 \mathrm{~g}$ \\
\hline & $\mathrm{CaCl}_{2} \cdot 2 \mathrm{H}_{2} \mathrm{O}$ & $0.044 \mathrm{~g}$ \\
\hline & $\mathrm{KCl}$ & $0.074 \mathrm{~g}$ \\
\hline & $\mathrm{MgSO}_{4} \cdot 7 \mathrm{H}_{2} \mathrm{O}$ & $1.23 \mathrm{~g}$ \\
\hline & $\mathrm{NaHCO}_{3}$ & $0.84 \mathrm{~g}$ \\
\hline & $\mathrm{FeC}_{6} \mathrm{H}_{5} \mathrm{O}_{7}$ & $0.002 \mathrm{~g}$ \\
\hline & UPW & $1000 \mathrm{~mL}$ \\
\hline \multirow{7}{*}{ A5 } & $\mathrm{H}_{3} \mathrm{BO}_{3}$ & $286 \mathrm{mg}$ \\
\hline & $\mathrm{MnCl}_{2} \cdot 4 \mathrm{H}_{2} \mathrm{O}$ & $181 \mathrm{mg}$ \\
\hline & $\mathrm{ZnSO}_{4} \cdot 7 \mathrm{H}_{2} \mathrm{O}$ & $22.2 \mathrm{mg}$ \\
\hline & $\mathrm{Na}_{2} \mathrm{MoO}_{4} \cdot 2 \mathrm{H}_{2} \mathrm{O}$ & $39 \mathrm{mg}$ \\
\hline & $\mathrm{CuSO}_{4} \cdot 5 \mathrm{H}_{2} \mathrm{O}$ & $7.9 \mathrm{mg}$ \\
\hline & $\mathrm{Co}\left(\mathrm{NO}_{3}\right)_{2} \cdot 6 \mathrm{H}_{2} \mathrm{O}$ & $4.9 \mathrm{mg}$ \\
\hline & UPW & $100 \mathrm{~mL}$ \\
\hline
\end{tabular}

\subsection{Observations of Cell Morphology and Determination of Absorbance}

A small amount of Dunaliella was fixed with Luger's reagent and the morphology of the algal cells was observed under an Olympus BX-51 microscope (Olympus Corp, Tokyo, Japan), equipped with a DP72 digital camera. 
Three $\mathrm{mL}$ of the algae liquid was used to measure the peak absorbance value with an ultraviolet-visible spectrophotometer (TU-1810, Persee, Auburn, CA, USA), and the result was $686 \mathrm{~nm}$. The absorbance value was measured once every two days [16].

All experiments were performed three times to ensure the accuracy of the data. The values were expressed as mean \pm SD of three parallel measurements. A one-way analysis of variance (ANOVA) in SPSS software was used to evaluate the significance of the differences between algae. $p<0.05\left(^{*}\right)$ indicated the presence of a statistically significant difference, $\left.p<0.01{ }^{* *}\right)$ was considered highly significant, and $p>0.05$ meant no significant difference.

\subsection{Determination of Photosynthetic Pigment Content and the Chlorophyll Fluorescence Parameters}

The determination of the chlorophyll content is based on Mera's method with some modifications [17]: Take $6 \mathrm{~mL}$ of algal liquid in a $10 \mathrm{~mL}$ centrifuge tube, centrifuge at $4500 \times g$ for $5 \mathrm{~min}$, pour out the supernatant, add $5 \mathrm{~mL}$ of $95 \%$ ethanol, mix well, put it in a refrigerator at $4{ }^{\circ} \mathrm{C}$ for $24 \mathrm{~h}$, take it out for $8000 \times \mathrm{g}$ of centrifuge for $10 \mathrm{~min}$, filter the supernatant with a $0.45 \mu \mathrm{m}$ filter, put $3 \mathrm{~mL}$ into the cuvette of the UV-Vis spectrophotometer, and measure the OD values at 649,665, and $470 \mathrm{~nm}$ wavelengths; calculate the content of Chlorophyll $a(\mathrm{Chl} a)$, Chlorophyll $b(\mathrm{Chl} b)$, and Carotenoid (Car) according to the following formulas, all in $\mathrm{mg} / \mathrm{L}$.

$$
\begin{gathered}
\text { Chlorophyll } a(\mathrm{mg} / \mathrm{mL})=13.95 \times \text { OD }(665 \mathrm{~nm})-668 \times \text { OD }(649 \mathrm{~nm}) \\
\text { Chlorophyll } b(\mathrm{mg} / \mathrm{mL})=24.96 \times \text { OD }(649 \mathrm{~nm})-7.32 \times \text { OD }(665 \mathrm{~nm}) \\
\text { Carotenoids }(\mathrm{mg} / \mathrm{mL})=\frac{(1000 \times \mathrm{OD}(470 \mathrm{~nm})-2.05 \times \mathrm{Chl} \mathrm{a}-114.8 \times \mathrm{Chl} \mathrm{b})}{245}
\end{gathered}
$$

The chlorophyll fluorescence parameters were measured using a previous method [18]: Put $3 \mathrm{~mL}$ of the Dunaliella sample solution in a centrifuge tube, then wrap it in tin foil, and treat it in the dark for $30 \mathrm{~min}$; use a portable PAM chlorophyll fluorometer (AquaPen-CAPC 100, Ecotech, Shanghai, China) to sequentially determine the Fv/Fm and Fv / Fo ratios of each algal solution, and use the professional FluorPen software for data transmission and analysis.

\subsection{Determination of $\beta$-Carotene Content}

The $\beta$-carotene standard curve was established following a previous method [19]. Two liters of a mixture of acetone and petroleum ether were prepared at a ratio of 3:1.

Six mL of algal liquid was crushed with an ultrasonic crusher (SCIENTZ-IID, Scientz, Ningbo, China); after extracting $\beta$-carotene with acetone-petroleum ether mixture, the $\beta$ carotene content was determined by spectrophotometry [20]. The absorbance was measured at $452 \mathrm{~nm}$ after the liquid was concentrated. $\beta$-carotene content was determined according to the Biaoqu formula.

\subsection{Determination of the GGPS Activity}

Forty-five $\mathrm{mL}$ of algal liquid was repeatedly frozen and thawed after crushing with an ultrasonic crusher, using a kit (ELISA, FanKew, Shanghai, China) to measure the GGPS activity. A microplate reader (Epoch2, BioTek, Winooski, VT, USA) was used to measure the absorbance at $450 \mathrm{~nm}$, and the Biaoqu formula was used to calculate the GGPS activity.

\subsection{Amplification, Sequencing, and Characterization of GGPS in Dunaliella}

The TaKaRa MiniBEST Universal RNA Extraction Kit (Takara, Shiga, Japan) was used for the extraction of RNA from Dunaliella. The PrimeScript ${ }^{\mathrm{TM}}$ RT reagent Kit with gDNA Eraser (Takara, Shiga, Japan) was used for reverse transcription. The cDNA sequences for GGPS genes in Dunalella saline which have been published in the NCBI were downloaded and divided into three cDNA sequence fragments with repeating areas. Using them as a template to design primers for the NCBI, three primers were obtained, and the results are 
shown in Table 3; the primers required for the three-stage nested PCR were synthesized by Sangon Biotech (Shanghai, China). Using them to amplify the cDNA in Dunaliella and then using the SEQUENTER software to splice between three sequences, the splicing sites are at $534 \pm 11 \mathrm{bp}$ and $800 \pm 10 \mathrm{bp}$. Finally, the length of the GGPS gene in the 15 Dunaliella species is $1715 \pm 15 \mathrm{bp}$.

Table 3. The primer names are A, B, and C, respectively. $\mathrm{Tm}^{\prime}$ is the representative annealing temperature.

\begin{tabular}{crrr}
\hline Primer & Forward Primer & Reverse Primer & Tm $^{\prime}$ \\
\hline A & $5^{\prime}$-AAGAGCGAAAACGAGGAGGT-3 & $5^{\prime}$-ATTCAGGGCGCTTCAAGGTT-3 & $56{ }^{\circ} \mathrm{C}$ \\
B & $5^{\prime}$-GGTGCACACCATGAGCCT-3' & $5^{\prime}$-TGGCAGGGCACTGCTCTTA-3' & $56^{\circ} \mathrm{C}$ \\
C & $5^{\prime}$-AGGGGGTTGTAGACCGTGTT-3 $3^{\prime}$ & $5^{\prime}$-CTCCACTGTCACGTCGTCCG-3 & $54^{\prime} \mathrm{C}$ \\
\hline
\end{tabular}

The PCR reaction system was $20 \mu \mathrm{L}$, including $2 \mu \mathrm{L}$ of template cDNA, $2 \mu \mathrm{L}$ of $\mathrm{dNTP}, 2 \mu \mathrm{L}$ of DNA buffer, $0.2 \mu \mathrm{L}$ of Easy Taq enzyme, $2 \mu \mathrm{L}$ of upstream primer, $2 \mu \mathrm{L}$ of downstream primer, and $9.8 \mu \mathrm{L}$ of ultrapure water.

The PCR amplification program was $94{ }^{\circ} \mathrm{C}$ pre-denaturation for $3 \mathrm{~min}, 94{ }^{\circ} \mathrm{C}$ denaturation for $1 \mathrm{~min}, \mathrm{Tm}^{\prime}$ annealing for $1 \mathrm{~min}, 72^{\circ} \mathrm{C}$ of extension for $1.30 \mathrm{~min}$ and $40 \mathrm{cycles}$, and a $72{ }^{\circ} \mathrm{C}$ extension for $10 \mathrm{~min}$. The products were stored at $4{ }^{\circ} \mathrm{C}$.

The amplified products were electrophoresed (DYY-7C, LIUYI, Shanghai, China) on a $1 \%$ agarose gel. After sequencing, the Sequencher software was used to (https: / / www.sequencher.cn / (accessed on 23 November 2021)) splice the sequence and obtain the GGPS nucleotide sequence.

MEGA 7 and Clustal W software were used to analyze the genetic distance of the GGPS genes from the 15 Dunaliella species [21-23]. The phylogenetic tree of the Dunaliella GGPS gene was constructed using the neighbor-joining method [24]. The online tool, TMHMM-2.0, and a protein domain database (SMART database: http://smart.emblheidelberg.de/ (accessed on 23 November 2021)) were used to analyze the protein transmembrane situation of the GGPS between different species.

\section{Results}

\subsection{Dunaliella Growth and Cell Morphology}

Figure 1 shows the state of the algae liquid when the 15 species of Dunaliella were cultured in an Erlenmeyer flask for 40 days, and Figure 2 and Table 4 show the microscopic morphology of the algal cells after 40 days of culture. The results showed that the color of the algae cells of 15 species of Dunaliella was green. The algae cells of D2, D5, and D15 are pear-shaped, D8, D9, and D10 are round, and the others are oval. The algal cells of D2, D4, D5, D6, D7, D8, D11, D12, D13, and D14 have flagella. Among the 15 Dunaliella species, D8 has the largest individual cell with a length and width of $10.25 \pm 2 \mu \mathrm{m}$, and D9 has the smallest individual cell with a length and width of $6.9 \pm 0.5 \mu \mathrm{m}$ and $4.6 \pm 0.2 \mu \mathrm{m}$, respectively. For the remaining 13 strains of Dunaliella, the overall width range of the algae cells is 3.8-8.4 $\mu \mathrm{m}$, and the height range is $6.5-10.3 \mu \mathrm{m}$. For the cell height, with width as a single factor, a one-way analysis of variance was performed, and pairwise comparisons were made. The results are shown in Table 4 . When the letter marks are the same, it means that there is no significant difference between them. According to the markers in Table 4, D8 is marked as B, D1 and D15 are marked as A, and the other 12 Dunaliella strains are marked with AB. It means that there is a significant difference between D8 and D1, D15, $p<0.05$. The 15 strains of Dunaliella have no obvious differences as a whole.

Figure 3 shows that a small amount of algae was inoculated into a tapered bottle containing a Dunaliella medium, and the growth and reproduction of the algal cells was slow at days one to seven. The algal cells grew rapidly, and their density was high beginning from the 8th day into the logarithmic growth phase. After about 45 days, the algal species entered the mature stage, and the growth rate slowed. Among the 15 Dunaliella species, D3 grew the worst, and D15 grew the best. 


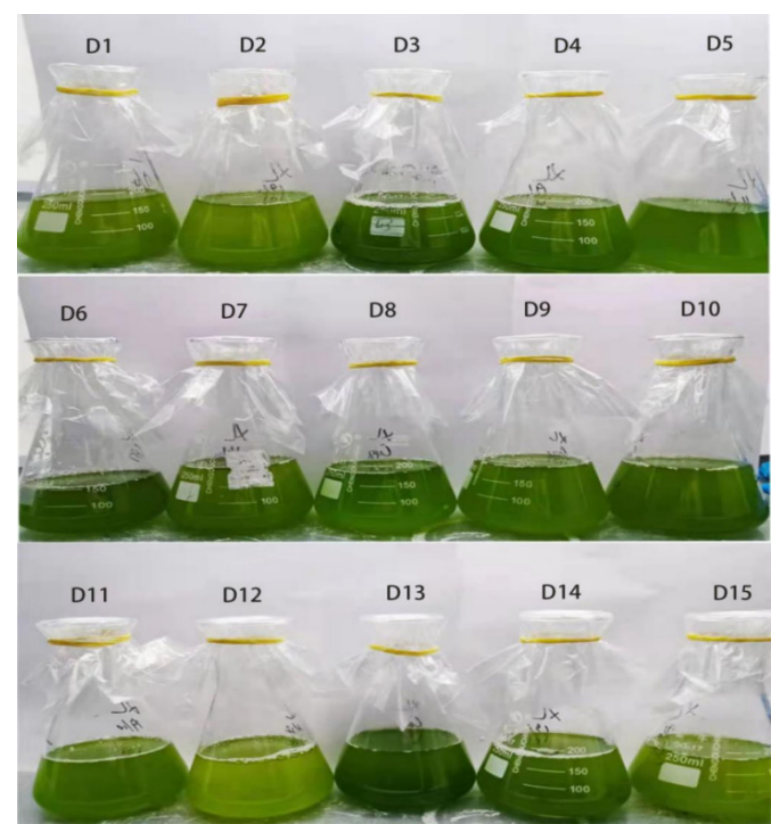

Figure 1. Appearance of the 15 Dunaliella species in Erlenmeyer flasks after 40 days of culture.

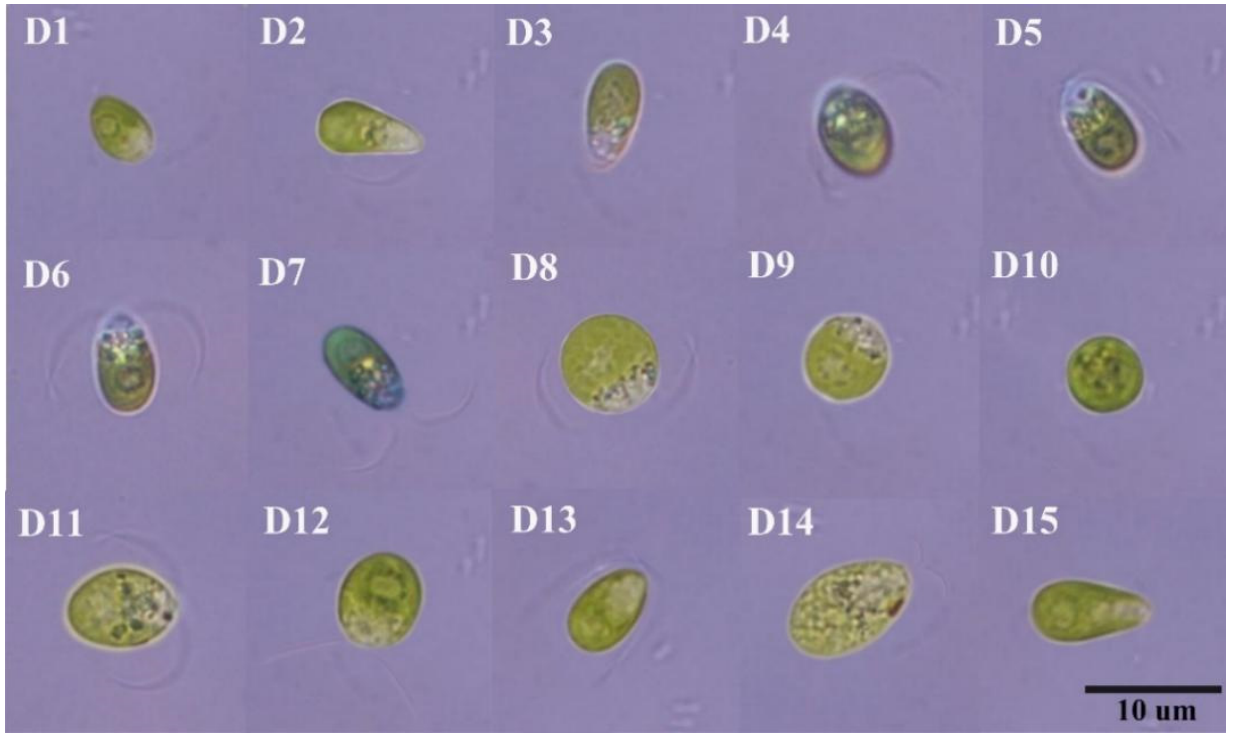

Figure 2. Algal cell morphology of the 15 species of Dunaliella $(100 \times)$.

Table 4. Description of the cell characteristics of the 15 Dunaliella species. The length/width of the cell is used as a single factor for single-factor analysis of variance, and the results are represented by $\mathrm{A}$ and $\mathrm{B}$.

\begin{tabular}{llllll}
\hline \multicolumn{1}{c}{ Species } & No. & Height (H) & Width $\mathbf{( W )}$ & Shape & \multicolumn{1}{c}{$\begin{array}{c}\text { Anova } \\
\text { (H/W) }\end{array}$} \\
\hline D. primolecta & D1 & $7.7 \pm 0.8 \mu \mathrm{m}$ & $4 \pm 0.2 \mu \mathrm{m}$ & Oval & $\mathrm{A}$ \\
D. maritima & $\mathrm{D} 2$ & $8.3 \pm 1.2 \mu \mathrm{m}$ & $6.3 \pm 0.9 \mu \mathrm{m}$ & Pear & $\mathrm{AB}$ \\
D. peircei & $\mathrm{D} 3$ & $7.3 \pm 0.6 \mu \mathrm{m}$ & $7.3 \pm 0.5 \mu \mathrm{m}$ & Oval & $\mathrm{AB}$ \\
D. viridis & $\mathrm{D} 4$ & $9 \pm 1.3 \mu \mathrm{m}$ & $7 \pm 1 \mu \mathrm{m}$ & Oval & $\mathrm{AB}$ \\
D. bioculata & $\mathrm{D} 5$ & $8.7 \pm 1.1 \mu \mathrm{m}$ & $4.7 \pm 0.3 \mu \mathrm{m}$ & Pear & $\mathrm{AB}$ \\
D. quartolecta & $\mathrm{D} 6$ & $9 \pm 1.3 \mu \mathrm{m}$ & $7 \pm 1.2 \mu \mathrm{m}$ & Oval & $\mathrm{AB}$ \\
D. parva & $\mathrm{D} 7$ & $9.3 \pm 1.2 \mu \mathrm{m}$ & $6.3 \pm 1.1 \mu \mathrm{m}$ & Oval & $\mathrm{AB}$ \\
D. salina & $\mathrm{D} 8$ & $10.3 \pm 2 \mu \mathrm{m}$ & $10.3 \pm 1.9 \mu \mathrm{m}$ & Round & $\mathrm{B}$ \\
\hline
\end{tabular}


Table 4. Cont.

\begin{tabular}{llllll}
\hline \multicolumn{1}{c}{ Species } & No. & Height $(\mathbf{H})$ & Width $\mathbf{( W )}$ & Shape & \multicolumn{1}{c}{$\begin{array}{c}\text { Anova } \\
\text { (H/W) }\end{array}$} \\
\hline D. polymorpha & D9 & $6.9 \pm 0.5 \mu \mathrm{m}$ & $4.6 \pm 0.2 \mu \mathrm{m}$ & Round & $\mathrm{AB}$ \\
D. tertiolecta & $\mathrm{D} 10$ & $7.3 \pm 0.8 \mu \mathrm{m}$ & $6.7 \pm 0.8 \mu \mathrm{m}$ & Round & $\mathrm{AB}$ \\
D. acidophila & $\mathrm{D} 11$ & $9.3 \pm 1.1 \mu \mathrm{m}$ & $6.9 \pm 0.5 \mu \mathrm{m}$ & Oval & $\mathrm{AB}$ \\
D. bioculata_C33 & $\mathrm{D} 12$ & $8.7 \pm 1 \mu \mathrm{m}$ & $6.7 \pm 0.8 \mu \mathrm{m}$ & Oval & $\mathrm{AB}$ \\
D. salina_42 & $\mathrm{D} 13$ & $9.2 \pm 1.5 \mu \mathrm{m}$ & $7.2 \pm 1.2 \mu \mathrm{m}$ & Oval & $\mathrm{AB}$ \\
Dunaliella sp. & $\mathrm{D} 14$ & $8.7 \pm 1 \mu \mathrm{m}$ & $6.8 \pm 1 \mu \mathrm{m}$ & Oval & $\mathrm{AB}$ \\
D. apiculata & $\mathrm{D} 15$ & $9.7 \pm 1.4 \mu \mathrm{m}$ & $6.7 \pm 0.7 \mu \mathrm{m}$ & Pear & $\mathrm{A}$ \\
\hline
\end{tabular}
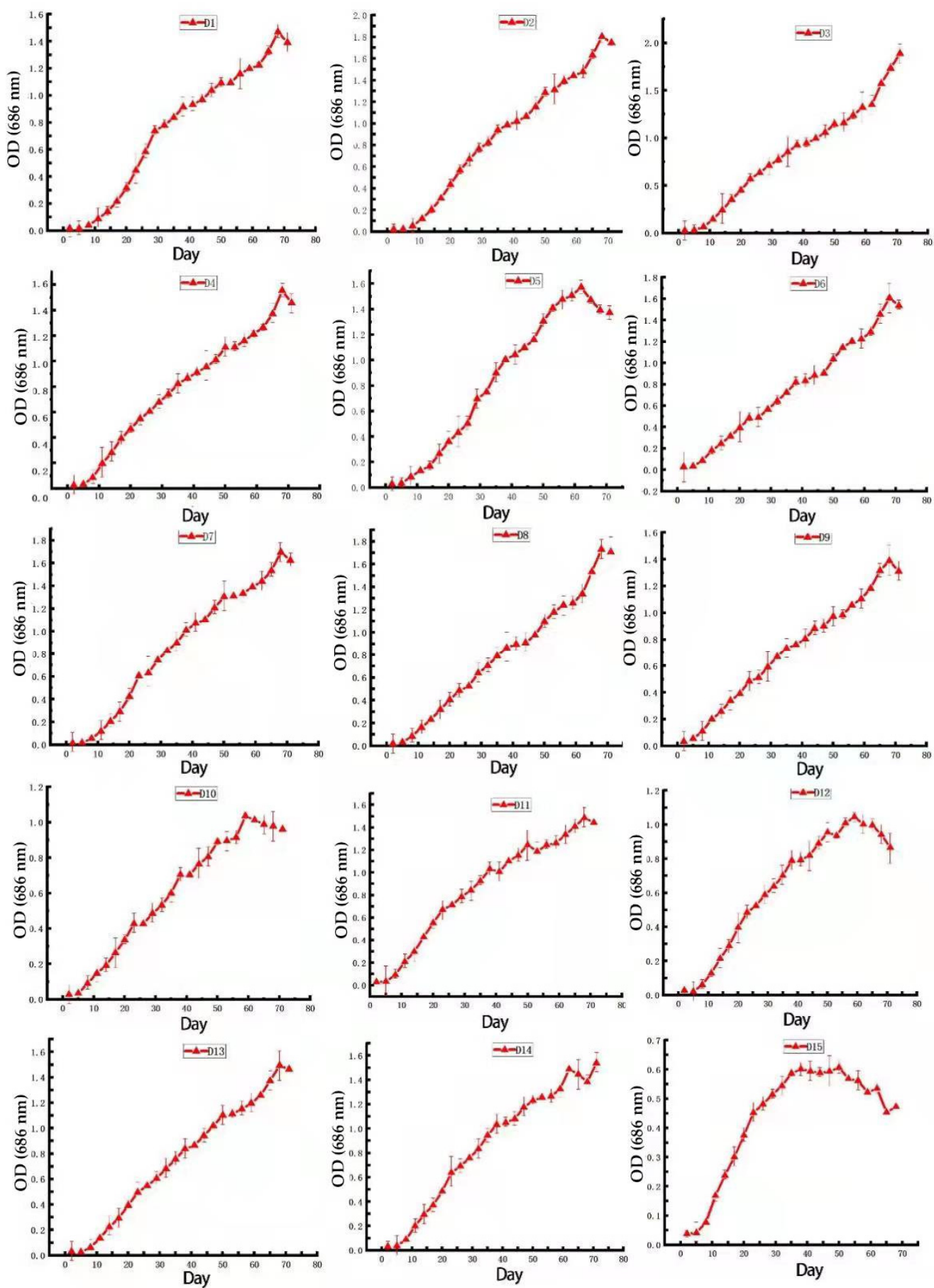

Figure 3. Growth changes in the 15 Dunaliella species. 


\subsection{Comparison of Photosynthetic Pigment Contents and Chlorophyll Fluorescence Parameters}

Supplementary Figures S1-S3, respectively, show the changes in chlorophyll $a$, chlorophyll $b$, and carotenoid contents in the 15 Dunaliella species. All three pigments increased over time. Among them, the chlorophyll $a$, chlorophyll $b$, and carotenoids of D8 are the largest (chlorophyll $a$ content is $19.58 \mathrm{mg} / \mathrm{mL}$, chlorophyll $b$ content is $10.3 \mathrm{mg} / \mathrm{mL}$, carotenoid content is $6.4 \mathrm{mg} / \mathrm{mL}$ ). Compared with 14 other Dunaliella strains, D15 has the lowest chlorophyll and carotenoid content (chlorophyll $a$ content is $7.30 \mathrm{mg} / \mathrm{mL}$, and the carotenoid content is $1.881 \mathrm{mg} / \mathrm{mL}$ ). It shows that the chlorophyll and carotenoid synthesis in different Dunaliella varies, but the overall change trend has gradually accumulated over time. D8 can be used as a selected algae species of chlorophyll and carotenoids in Dunaliella.

The Fv/Fo and Fv/Fm values of the 15 Dunaliella species changed similarly, they all increased first and then decreased (Supplementary Figures S4 and S5). The D2, D6, D8, and D14 species reached the maximum on day eight; the D1, D7, D9, D10, and D13 species reached the maximum on day 11, and the D3, D5, D6, D11, D12, and D15 species reach the maximum on day 15 . It shows that the chlorophyll fluorescence parameters in different Dunaliella have differentiation, but the overall change trend is the same, and they are decreasing first.

\subsection{Comparison of $\beta$-Carotene Content}

Using $\beta$-carotene powder as the standard, the regression equation for the standard curve was (correlation coefficient $=0.9945)$ :

$$
\mathrm{Y}=0.2687 \mathrm{x}-0.0051
$$

Figure 4 shows that the $\beta$-carotene content of Dunaliella at the mature stage was significantly higher than that during the logarithmic stage, indicating that the $\beta$-carotene content accumulated over time. The D1 strain had the highest $\beta$-carotene content of $10.19 \times 10^{-2} \mathrm{mg} / \mathrm{mL}$, and D15 had the lowest $\beta$-carotene content of $4.3 \times 10^{-2} \mathrm{mg} / \mathrm{mL}$.

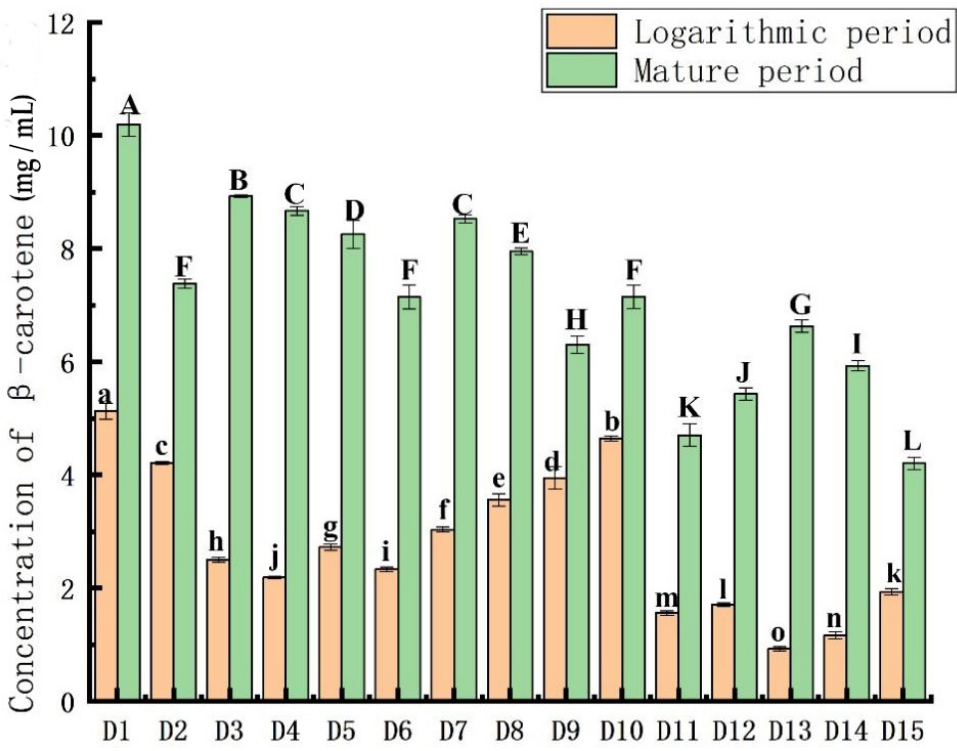

Figure 4. Comparison of $\beta$-carotene content in the 15 Dunaliella strains. The letters a-i and A-L in the figure represent the single-factor significant difference analysis of the $\beta$-carotene content in 15 Dunaliella strains at the logarithmic and mature stages, respectively. When the letters marked on different Dunaliella species are the same, it means that there is no significant difference between them, and when the letters are different, there is a significant difference.

The specific comparison during the logarithmic phase was: D1 > D10 > D2 > D9 > D8 $>$ D7 $>$ D5 > D3 > D6 > D4 > D15 > D12 > D11 > D14 > D13. In the logarithmic phase, 
the one-way analysis of variance for $\beta$-carotene is indicated by lowercase letters a-o. The results showed that the $\beta$-carotene content of 15 Dunaliella species in the logarithmic phase were all significantly different, $p<0.05$.

The specific comparison during the mature phase was: D1 $>$ D3 $>$ D1 $>$ D4 $>$ D7 $>$ D8 $>$ D10 $>$ D2 $>$ D6 $>$ D13 $>$ D9 $>$ D14 $>$ D12 $>$ D11 $>$ D15. In the mature period, the single-factor significant difference analysis of $\beta$-carotene is indicated by capital letters A-L. The results showed that D2, D6, and D10 had no significant difference, D4 and D7 had no significant difference, $p>0.05$, and the other 10 Dunaliella species had significant differences, $p<0.05$.

\subsection{Comparison of GGPS Activity}

Figure 5 shows that the total GGPS activity was significantly lower during the mature phase than during the logarithmic phase.

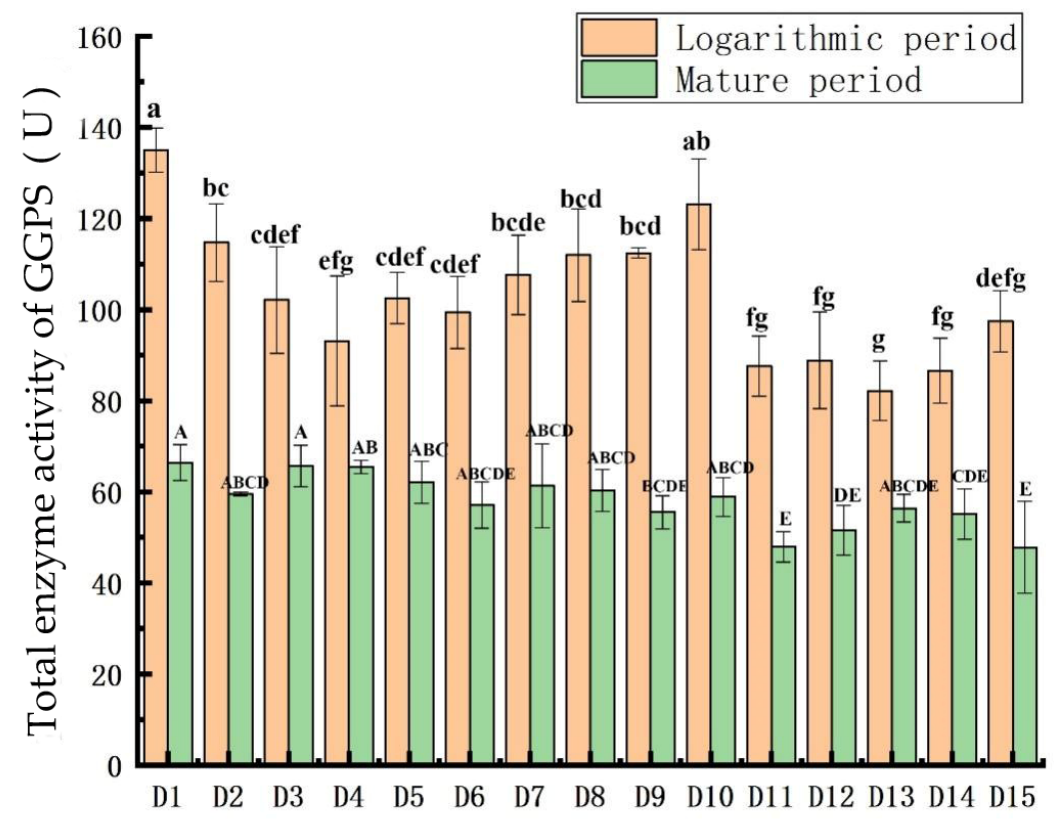

Figure 5. Comparison of GGPS activity in the 15 Dunaliella strains. The letters a-g and A-E in the figure represent the single-factor significant difference analysis of the GGPS total enzyme activity content of 15 Dunaliella strains in the logarithmic and mature stages, respectively. When the letters marked on different Dunaliella species are the same, it means that there is no significant difference between them, and when the letters are different, it means that there is a significant difference.

The specific comparison during the logarithmic phase was: D1 $>$ D10 > D2 > D9 > D8 $>$ D7 $>$ D5 > D3 > D6 > D15 > D4 > D12 > D11 > D14 > D13. In the logarithmic phase, the one-way analysis of variance of GGPS enzyme activity is represented by lowercase letters a-g. The results show that, except for D10, D1 is significantly different from the other 13 algae; except for D2, D7, D8 and D9, D10 is significantly different from the other 10 algae; except for D11, D12, D14 and D15, D13 has significant differences from the other 10 species of algae $(p<0.05)$.

The specific comparison during the mature phase was: D1 $>$ D3 $>$ D1 $>$ D4 $>$ D7 $>$ D8 $>$ D2 > D10 > D6 > D13 > D9 > D14 > D12 > D11 > D15. In the mature period, the one-way analysis of variance of the GGPS enzyme activity is represented by capital letters A-E. The result shows that D1 is significantly different from D9, D11, D14, and D15; D11 is significantly different from D2, D3, D4, D5, D7, D8, and D10 $(p<0.05)$.

\subsection{Relationship between $\beta$-Carotene Content and GGPS Activity}

Figure 6 shows the linear relationship between $\beta$-carotene and the GGPS enzyme activity. In the logarithmic period, the formula for the linear relationship between the two is: $y=0.0855 x-6.0357$, and the coefficient is 0.9632 . In the mature period, the formula 
for the linear relationship between the two is: $y=0.2753 x-8.8265$, and the coefficient is 0.9569. It can be seen that the relationship between the two is linear and positive.

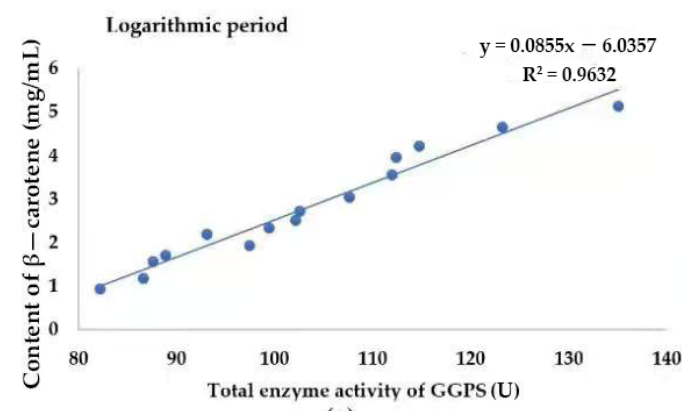

(a)

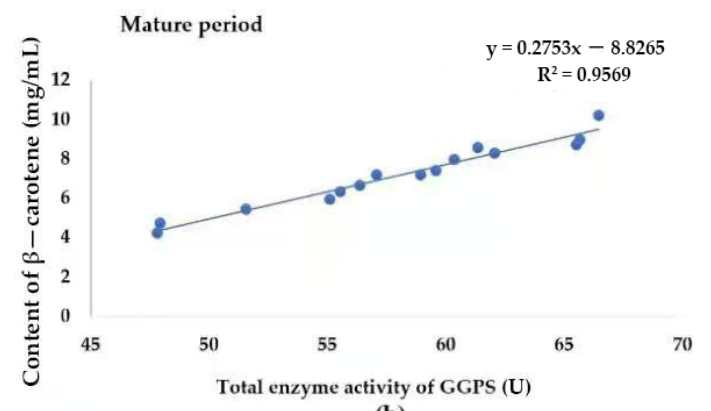

(b)

Figure 6. Linear relationship of $\beta$-carotene and GGPS enzyme activity in two periods. (a) In the logarithmic period. (b) In the mature period.

\subsection{Amplification and Characterization of the GGPS Gene}

Figure 7 shows the cDNA sequence amplification results obtained after electrophoresis of the 15 Dunaliella species using PCR with three sets of different primers. The electrophoresis results are compared with Lane-Marker as the control standard, and the leftmost bp indicates the length of the strip. As can be seen, the amplification result is good, as all were positive and there were no contaminated bands. The amplified sequence length of primers $A$ and $C$ was about $1000 \mathrm{bp}$ and that of primer B was about $750 \mathrm{bp}$.

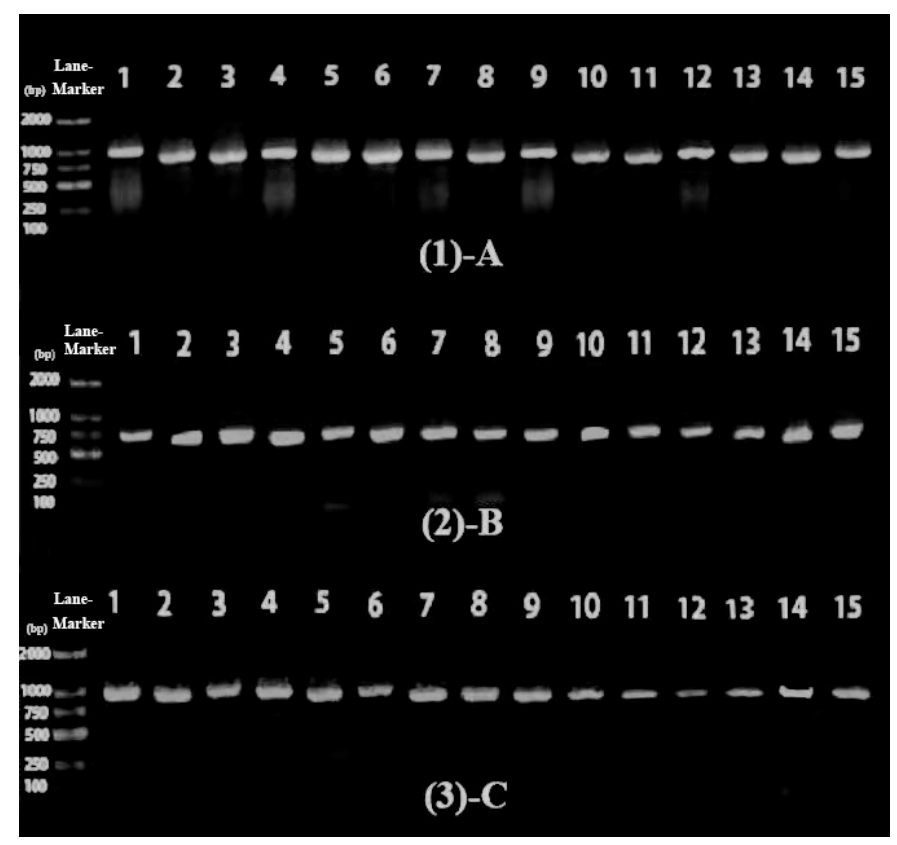

Figure 7. Lanes (1), (2), and (3) represent the cDNA amplification products, respectively, obtained by amplification with primers A, B, and C; from left to right: the D1, D2, D3, D4, D5, D6, D7, D8, D9, D10, D11, D12, D13, D14, and D15 species.

Table 5 shows the genetic distances of the GGPS genes among the 15 Dunaliella species. Among the 15 Dunaliella species, D8 and D13 were the same species of Dunaliella, and the genetic difference and genetic distances between them were zero; D5 and D12 were the same species of Dunaliella, and the genetic difference between them was 0.01 , with a genetic distance of $14 \mathrm{bp}$. The difference in the GGPS genes between the Dunaliella species was $0-3 \%$, and length was $0-43 \mathrm{bp}$. The GGPS genetic distances of the same Dunaliella species were quite different. 
Table 5. GGPS genetic distance among 15 Dunaliella species.

\begin{tabular}{|c|c|c|c|c|c|c|c|c|c|c|c|c|c|c|c|c|}
\hline & D8 & D10 & D7 & D5 & D2 & D1 & D9 & D11 & D13 & D15 & D14 & D3 & D6 & D12 & D4 & Chlamydomonas \\
\hline D8 & & 0 & 0 & 0 & 0 & 3 & 2 & 0 & 0 & 0 & 1 & 3 & 7 & 14 & 29 & 635 \\
\hline D10 & 0.00 & & 0 & 0 & 0 & 3 & 2 & 0 & 0 & 0 & 1 & 3 & 7 & 14 & 29 & 635 \\
\hline D7 & 0.00 & 0.00 & & 0 & 0 & 3 & 2 & 0 & 0 & 0 & 1 & 3 & 7 & 14 & 29 & 635 \\
\hline D5 & 0.00 & 0.00 & 0.00 & & 0 & 3 & 2 & 0 & 0 & 0 & 1 & 3 & 7 & 14 & 29 & 635 \\
\hline D2 & 0.00 & 0.00 & 0.00 & 0.00 & & 3 & 2 & 0 & 0 & 0 & 1 & 3 & 7 & 14 & 29 & 635 \\
\hline D1 & 0.00 & 0.00 & 0.00 & 0.00 & 0.00 & & 4 & 3 & 3 & 3 & 4 & 6 & 10 & 17 & 32 & 638 \\
\hline D9 & 0.00 & 0.00 & 0.00 & 0.00 & 0.00 & 0.00 & & 2 & 2 & 2 & 3 & 5 & 9 & 16 & 31 & 637 \\
\hline D11 & 0.00 & 0.00 & 0.00 & 0.00 & 0.00 & 0.00 & 0.00 & & 0 & 0 & 1 & 3 & 7 & 14 & 29 & 635 \\
\hline D15 & 0.00 & 0.00 & 0.00 & 0.00 & 0.00 & 0.00 & 0.00 & 0.00 & 0.00 & & 1 & 3 & 7 & 14 & 29 & 635 \\
\hline D14 & 0.00 & 0.00 & 0.00 & 0.00 & 0.00 & 0.00 & 0.00 & 0.00 & 0.00 & 0.00 & & 4 & 8 & 15 & 30 & 635 \\
\hline D3 & 0.00 & 0.00 & 0.00 & 0.00 & 0.00 & 0.00 & 0.00 & 0.00 & 0.00 & 0.00 & 0.00 & & 10 & 17 & 30 & 637 \\
\hline D6 & 0.00 & 0.00 & 0.00 & 0.00 & 0.00 & 0.01 & 0.01 & 0.00 & 0.00 & 0.00 & 0.00 & 0.01 & & 21 & 32 & 639 \\
\hline D12 & 0.01 & 0.01 & 0.01 & 0.01 & 0.01 & 0.01 & 0.01 & 0.01 & 0.01 & 0.01 & 0.01 & 0.01 & 0.01 & & 43 & 637 \\
\hline D4 & 0.02 & 0.02 & 0.02 & 0.02 & 0.02 & 0.02 & 0.02 & 0.02 & 0.02 & 0.02 & 0.02 & 0.02 & 0.02 & 0.03 & & 640 \\
\hline Chlamydomonas & 0.39 & 0.39 & 0.39 & 0.39 & 0.39 & 0.39 & 0.39 & 0.39 & 0.39 & 0.39 & 0.39 & 0.39 & 0.39 & 0.39 & 0.39 & \\
\hline
\end{tabular}


The GGPS genes of the 15 species of Dunaliella were phylogenetically analyzed by constructing a neighbor-joining tree, and the GGPS gene of Chlamydomonas reinhardtii was selected as the outgroup. The results are shown in Figure 8. As a result, the GGPS genes of the 15 species of Dunaliella were classified as one big branch. The large branch was divided into two smaller branches. The D4 strain formed a small branch alone, which was relatively but distantly related to the other 14 Dunaliella species.



Figure 8. GGPS phylogenetic tree of the 15 Dunaliella species based on the neighbor-joining algorithm.

Combining the phylogenetic tree with the above-mentioned genetic distance analysis showed that the GGPS genes have high homology, but the genetic distance between the same species was relatively high, and the establishment support rate was low, which was not suitable for classifying the same species.

In addition, the analysis of the protein transmembrane domain of the GGPS gene in the 15 species of Dunaliella species showed that GGPS had no protein transmembrane domain.

\section{Discussion}

Fifteen species of Dunaliella were cultured with the Dunaliella medium, and the algae cells of Dunaliella without cell walls were observed under a microscope; the shapes were mainly oval, pear-shaped, or round. The 15 species of Dunaliella are different in morphology, size, and growth cycle. The reason for the difference lies not only in the difference in algae, but also in the growth rate and suitable salinity of each algae strain $[25,26]$. Among the 15 Dunaliella species, D8 has the largest individual cell. This result is consistent with the results of Borowitzk's research [27].

Chlorophyll fluorescence parameters are important indicators for evaluating microalgae growth, photosynthesis, and cold and heat tolerance $[28,29]$. The changes in the ratio of $\mathrm{Fv} / \mathrm{Fm}$ and $\mathrm{Fv} / \mathrm{Fo}$ during the growth process reflect the changes in the photosynthetic activity of the Dunaliella species; the trends all increase first and then decrease. Oukarroum studied the changes of the chlorophyll fluorescence parameters during the growth of Chlorella [30], which result in the same as this article.

The photosynthetic pigments and $\beta$-carotene content accumulated with time. The D1 strain (D. primolecta) had the highest $\beta$-carotene content, and D8 (D. salina) had the highest 
photosynthetic pigment contents, suggesting its use in industrial production. Liu [31] compared the $\beta$-carotene content of ten Dunaliella species, and the results showed that $D$. salina was the highest and D. parva was the lowest, which was different from the results determined here. The reason for the difference may be due to different habitats, different culture conditions, or different $\beta$-carotene extraction methods. It is also possible that the algal species changed during long-term culture.

GGPS catalyzes the formation of GGPP from IPP and DMAPP. GGPP forms $\beta$-carotene under the catalysis of PSY, PDS, ZDS, CRTISO, ZISO, and LCYB. Sun's research on methods to increase the production of $\beta$-carotene showed that the addition of GGPS can increase the production of $\beta$-carotene [32]. The result is consistent with the positive correlation between $\beta$-carotene and the GGPS enzyme activity in this paper.

Preetha used ITS and 18S rDNA to study the phenotype and genetic diversity of different Dunaliella species from Indian salt marshes [33], and the results showed that D.viridis and D. salina, D. bioculata, D. parva, D. primolecta, and D. tertiolecta are relatively distantly related, and the same species of Dunaliella converge into a branch. In this paper, the phylogenetic analysis of the GGPS gene in Dunaliella shows that D4 (D. viridis) has a relatively distant relationship with the other 14 Dunaliella species. D8 and D13 are both D. salina, and D5 and D12 are both D. bioculata, but the same species do not form independent branches. Combining the above comparison and the analysis of genetic distance, it can be seen that GGPS is not suitable as a reference gene for the classification of Dunaliella species.

\section{Conclusions}

Fifteen species of Dunaliella were used to determine the changes in the photosynthetic pigment content, chlorophyll fluorescence parameters, $\beta$-carotene content, and GGPS activity. The results showed that Dunaliella existed in the form of a single oval, pear-shaped, or round, light green cells without a cell wall, but there were some differences in the sizes of the different species, D8 has the largest individual algae cell, and D9 has the smallest individual. Growth was relatively slow during days one through seven, a growth stagnation period. About eight days after entering the logarithmic growth phase, the cells grew rapidly to a high density. After about 45 days, they entered the mature period, and their growth slowed. The contents of chlorophyll, carotenoids, and $\beta$-carotene increased over time. The accumulation of $\beta$-carotene mainly occurred during the mature period. The $\beta$-carotene content of D1 was the highest. The species with high GGPS activity also had high $\beta$-carotene content. The phylogenetic analysis showed that the GGPS proteins of the 15 species were highly homologous, and there were no transmembrane proteins.

Supplementary Materials: The following are available online at https:/ /www.mdpi.com/article/10 .3390/plants11010027/s1, Figure S1: Changes in chlorophyll $a$ content in the 15 Dunaliella species, Figure S2: Changes in chlorophyll $b$ content in the 15 Dunaliella species, Figure S3: Changes in carotenoid content in the 15 Dunaliella species, Figure S4: Changes in the Fv/Fo ratio in the 15 Dunaliella species, Figure S5: Changes in the Fv/Fm ratio in the 15 Dunaliella species.

Author Contributions: Conceptualization, S.X. and F.G.; data curation, L.X.; formal analysis, L.X., F.G., J.F., J.L., Q.L., F.N. and X.L.; funding acquisition, S.X. and F.G.; writing-original draft, L.X.; writing-review \& editing, S.X. All authors have read and agreed to the published version of the manuscript.

Funding: This research was financed by the National Natural Science Foundation of China (Grant No. 41871037), the Scientific and Technological Innovation Programs of Higher Education Institutions in Shanxi of China (Grant No. 2019L0041), and the Shanxi "1331 Project".

Data Availability Statement: Data available on request from the corresponding author.

Acknowledgments: We are grateful to K. William (North Carolina State University) for his editorial assistance with the English.

Conflicts of Interest: The authors declare no conflict of interest. 


\section{References}

1. Phadwal, K.; Singh, P.K. Isolation and characterization of an indigenous isolate of Dunaliella sp. for beta-carotene and glycerol production from a hypersaline lake in India. J. Basic Microbiol. 2003, 43, 423-429. [CrossRef] [PubMed]

2. Sadka, A.; Lers, A.; Zamir, A. A critical examination of the role of de novo protein synthesis in the osmotic adaptation of the halotolerant alga Dunaliella. FEBS Lett. 1989, 244, 93-98. [CrossRef]

3. Borowitzka, M.A. High-value products from microalgae their development and commercialisation. J. Appl. Phycol. 2013, 25, 743-756. [CrossRef]

4. Benamotz, A.; Avron, M. The biotechnology of cultivating the halotolerant alga Dunaliella. Trends Biotechnol. 1990, 8, 121-126. [CrossRef]

5. Arun, N.; Singh, D.P. A review on pharmacological applications of halophilic alga Dunaliella. Indian J. Geo-Mar. Sci. 2016, 45, 440-447.

6. Ben-Amotz, A. New Mode of Dunaliella Biotechnology: Two-phase Growth for Beta-Carotene Production. J. Appl. Phycol. 1995, 7, 65-68. [CrossRef]

7. Vanitha, A.; Narayan, M.S.; Murthy, K.N.C. Comparative study of lipid composition of two halotolerant alga, Dunaliella bardawil and Dunaliella salina. Int. J. Food Sci. Nutr. 2007, 58, 373-383. [CrossRef] [PubMed]

8. Del Campo, J.A.; García-González, M.; Guerrero, M.G. Outdoor cultivation of microalgae for carotenoid production: Current state and perspectives. Appl. Microbiol. Biotechnol. 2007, 74, 1163-1174. [CrossRef]

9. Hosseini, T.A.; Shariati, M. Dunaliella biotechnology: Methods and applications. J. Appl. Microbiol. 2009, 107, 14-35. [CrossRef] [PubMed]

10. Sui, Y.; Vlaeminck, S.E. Dunaliella microalgae for nutritional protein: An undervalued asset. Trends Biotechnol. 2020, 38, 10-12 [CrossRef]

11. Ye, Z.W.; Jiang, J.G.; Wu, G.H. Biosynthesis and regulation of carotenoids in Dunaliella: Progresses and prospects. Biotechnol. Adv. 2008, 26, 352-360. [CrossRef]

12. Shewmaker, C.K.; Sheehy, J.A.; Daley, M. Seed-specific overexpression of phytoene synthase: Increase in carotenoids and other metabolic effects. Plant J. 1999, 20, 401-412. [CrossRef]

13. Schmidt-Dannert, C. Engineering novel carotenoids in microorganisms. Curr. Opin. Biotechnol. 2000, 11, 255-261. [CrossRef]

14. Albrecht, V.; Klein, A.; Hugueney, P. Molecular cloning and functional expression in E. coli of a novel plant enzyme mediating $\zeta$-carotene desaturation. FEBS Lett. 1995, 372, 199-202. [CrossRef]

15. Wang, T.; Feng, J.; Xie, S.L. Effect of culture conditions on the content of $\beta$-carotene in Dunaliella. Sci. Technol. Food Ind. 2014, 35, 177-181.

16. Chisti, Y. Biodiesel from microalgae beats bioethanol. Trends Biotechnol. 2008, 26, 126-131. [CrossRef] [PubMed]

17. Mera, R.; Torres, E.; Abalde, J. Effect of sodium sulfate on the freshwater microalga Chlamydomonas moewusii: Implications for the optimization of algal culture media. J. Phycol. 2016, 52, 75-88. [CrossRef] [PubMed]

18. Markou, G.; Muylaert, K. Effect of light intensity on the degree of ammonia toxicity on PSII activity of Arthrospira platensis and Chlorella vulgaris. Bioresour. Technol. 2016, 216, 453-461. [CrossRef]

19. El-Baz, F.K.; Abdel Jaleel, G.A.; Saleh, D.O.; Hussein, R.A. Protective and therapeutic potentials of Dunaliella salina on agingassociated cardiac dysfunction in rats. Asian Pac. J. Trop. Biomed. 2018, 8, 403-410.

20. Lu, B.J.; Zhai, Y.X.B. Application of Thin Layer Chromatography in Food Analysis, 1st ed.; Peking University Press: Beijing, China, 1991; pp. 135-138.

21. Kumar, S.; Stecher, G.; Tamura, K. MEGA7: Molecular evolutionary genetics analysis version 7.0 for bigger datasets. Mol. Biol. Evol. 2016, 33, 1870-1874. [CrossRef]

22. Lemberkovics, E.; Kéry, A.; Simándi, B. Influence of extraction methods on the composition of essential oils. Acta Pharm Hung. 2004, 74, 166-170. [PubMed]

23. Higgins, D.G.; Sharp, P.M. Clustal: A package for performing multiple sequence alignment on a microcomputer. Elsevier 1988, 73 , 237-244. [CrossRef]

24. Telles, G.P.; Araújo, G.S.; Walter, M.E.M.T. Live neighbor-joining. BMC Bioinf. 2018, 19, 172. [CrossRef] [PubMed]

25. Chen, H.; Jiang, J.G. Osmotic responses of Dunaliella to the changes of salinity. J. Cell Physiol. 2009, 219, 251-2588. [CrossRef] [PubMed]

26. Polle, J.E.W.; Struwe, L.; Jin, E. Identification and characterization of a new strain of the unicellular green alga Dunaliella salina (Teod.) from Korea. J. Microbiol. Biotchnol. 2008, 18, 821-827.

27. Borowitzka, M.A.; Siva, C.J. The taxonomy of the genus Dunaliella (Chlorophyta, Dunaliella) with emphasis on the marine and halophilic species. J. Appl. Phycol. 2007, 19, 567-590. [CrossRef]

28. Rizza, F.; Pagani, D.; Stanca, A.M. Use of chlorophyll fluorescence to evaluate the cold acclimation and freezing tolerance of winter and spring oats. Plant Breed. 2001, 120, 389-396. [CrossRef]

29. Havaux, M.; Strasser, R.J.; Greppin, H. A theoretical and experimental analysis of the qP and qN coefficients of chlorophyll fluorescence quenching and their relation to photochemical and nonphotochemical events. Photosynth Res. 1991, $27,41-55$. [CrossRef] [PubMed]

30. Oukarroum, A. Change in Photosystem II Photochemistry During Algal Growth Phases of Chlorella vulgaris and Scenedesmus obliquus. Curr. Microbiol. 2016, 72, 692. [CrossRef] [PubMed] 
31. Liu, G.F.; Lou, S.L.; You, L.Y. Extraction and content comparison of $\beta$-carotene from ten species (Species) of Dunaliella. J. Xiamen Univ. Nat. Sci. 1995, 34, 94-98.

32. Sun, J.; Sun, X.X.; Tang, P.W. Molecular cloning and functional expression of two key carotene synthetic genes derived from Blakeslea trispora into E. coli for increased $\beta$-carotene production. Biotechnol. Lett. 2012, 34, 2077-2082. [CrossRef] [PubMed]

33. Preetha, K.; John, L.; Subin, C.S.; Vijayan, K.K. Phenotypic and genetic characterization of Dunaliella (Chlorophyta) from Indian salinas and their diversity. Aquat Biosyst. 2012, 8, 27. [CrossRef] [PubMed] 